\title{
Serum androgen bioactivity is low in children with premature adrenarche
}

\author{
Jani Liimatta', Saila Laakso', Pauliina Utriainen', Raimo Voutilainen'1, Jorma J. Palvimo², Tiina Jääskeläinen ${ }^{2,3}$ and
}

Jarmo Jääskeläinen'

BACKGROUND: Clinical findings in children with premature adrenarche (PA) correlate only partly with circulating levels of adrenal androgens. It is not known whether the prepubertal low circulating concentrations of testosterone $(T)$ and dihydrotestosterone, together with those of adrenal androgens, are capable of activating the androgen receptor.

METHODS: This cross-sectional study was performed at a university hospital. Circulating androgen bioactivity was measured in 67 prepubertal children with clinical signs of PA and 94 control children using a novel androgen bioassay.

RESULTS: Circulating androgen bioactivity was low in the PA and control children. In the subgroup of children $(n=28)$ with serum $T$ concentration over the assay sensitivity $(0.35 \mathrm{nmol} / \mathrm{l})$ and a signal in the androgen bioassay, we found a positive correlation between androgen bioactivity and serum $\mathrm{T}(r=0.50 ; P$ $<0.01)$ and the free androgen index $(r=0.61 ; P<0.01)$ and a negative correlation with serum sex hormone-binding globulin concentration $(r=-0.41 ; P<0.05)$.

CONCLUSION: Peripheral metabolism of adrenal androgen precursors may be required for any androgenic effects in PA. However, the limitations in the sensitivity of the bioassay developed herein may hide some differences between the PA and control children.

$\mathbf{T}$ he reticular zone (zona reticularis (ZR)) of the adrenal cortex starts to develop from small focal islets in early childhood (1). Later on, continuous ZR begins to produce weak androgen precursors, mostly dehydroepiandrosterone (DHEA) and its sulfate (DHEAS), and this phenomenon is referred to as adrenarche. During adrenarche, increasing androgenic activity leads to greasiness of the skin and hair, comedones/acne, adult-type body odor, and finally to the development of axillary and pubic hair. Though not uniformly used, adrenarche may be defined as premature (premature adrenarche (PA)) if these clinical signs are evident together with elevated serum levels of adrenal androgens before the age of $8 \mathrm{y}$ in girls or $9 \mathrm{y}$ in boys (2).

In both normal-timed and PA, the clinical signs of androgen activity do not correlate well with the circulating levels of
DHEA, DHEAS, or androstenedione (A4) (2,3). In peripheral tissues such as the skin, DHEA and DHEAS interconvert via hydroxysteroid sulfotransferase and steroid sulfatase (4), but DHEAS desulfonation in the liver is controversial (5). DHEAS is biologically inactive, and DHEA is only a weak androgen receptor (AR) agonist (6), but they are present in the serum of PA subjects in excess concentrations.

The effects of androgens are mediated via the AR, resulting in the activation of target gene transcription (7). Whereas testosterone $(\mathrm{T})$ and dihydrotestosterone (DHT) are potent AR agonists, the affinity of adrenal androgen precursors to AR is weak $(6,8)$, and prereceptor level conversion to more potent androgens is needed for the full activation of AR. In peripheral tissues, DHEA is converted to the most potent androgen, DHT, through A4 and T. The main enzymes responsible for this intracrine conversion are $3 \beta$-hydroxysteroid dehydrogenase 1 (HSD3B1), 17 $\beta$-hydroxysteroid dehydrogenase 5 (HSD17B5), and $5 \alpha$-reductase. Expression of these converting enzymes has been discovered in many peripheral tissues, including the skin epidermis, hair follicles, and dermal exocrine gland cells $(4,9,10)$, and the level of conversion varies in different cells (11). However, it is not known to what extent adrenal androgens are converted to $\mathrm{T}$ and DHT in the liver, or whether the androgens found in the circulation of PA subjects are able to induce further AR activation.

Peripheral intracrine prereceptor modulation of androgens and AR activity may be key points in explaining the variability of androgenic activity in PA. Recent studies have demonstrated that a shorter CAG repeat polymorphism in the $A R$ gene leading to increased transactivation efficacy of the receptor is associated with PA, especially among lean children $(12,13)$. On the other hand, factors regulating peripheral conversion and its efficiency, e.g., polymorphisms of peripheral steroidogenic enzymes, have been poorly studied to date. Polymorphisms in genes encoding HSD17B5 and aromatase have been studied by Petry et al. $(14,15)$ showing no significant association with premature pubarche. Variations in genes encoding steroid sulfatase, HSD3B1, and $5 \alpha$-reductase have not been studied in PA. However, Wang et al. (16) found significant differences in the gene encoding HSD3B1 in four different ethnic groups of

'Department of Pediatrics, University of Eastern Finland, Kuopio University Hospital, Kuopio, Finland; ${ }^{2}$ Institute of Biomedicine, University of Eastern Finland, Kuopio, Finland; ${ }^{3}$ Institute of Dentistry, University of Eastern Finland, Kuopio, Finland. Correspondence: Jarmo Jääskeläinen (jarmo.jaaskelainen@kuh.fi) 
adults. They also found decreased enzyme activity with common polymorphisms of the HSD3B1 in an in vitro luciferase (LUC) reporter gene assay (16). Thus, genetic variation in the peripheral metabolism of steroid hormones may be one factor explaining the phenotypic variability in children with PA from different ethnic backgrounds.

Furthermore, a recent study has shown HSD17B5 to be expressed in the human adrenal ZR from the age of $9 \mathrm{y}$, enabling the production of $\mathrm{T}$ (17), and it has been speculated that more potent adrenal androgens in addition to DHEA and DHEAS could increase circulating androgen activity during adrenarche (18).

Circulating androgen bioactivity can be studied using androgen bioassays that measure bioactivity directly from a small amount of human serum. The developed assays are based on cell lines transfected transiently or stably with the $A R$ and different androgen-responsive promoters that drive the expression of an easily measurable enzyme, usually LUC $(19,20)$. However, these assays have not yet been used to study androgen bioactivity in children with PA. In this study, we measured circulating androgen bioactivity in children with PA using a novel androgen bioassay. Our goal was to investigate whether potent androgens are produced or converted to the circulation in children with PA, and therefore, our choice for the cell line was COS-1 (CV-1 in origin, carrying the SV40 genetic material), in which the converting enzymes (including $5 \alpha$-reductase) are not expressed $(19,21)$.

\section{RESULTS}

\section{Androgenic Activity of Different Steroids}

Different androgens were studied for their ability to activate the AR-dependent reporter gene in COS-1 cells. All steroids at each concentration were compared with $\mathrm{T}$ at the concentration of $1 \mu \mathrm{mol} / \mathrm{l}(=1)$, and the experiments were performed two to three times. The results are presented in Figure 1. DHEA and DHEAS did not activate AR at the tested concentrations.

\section{Androgenic Activity of the Sera in the Studied Subjects}

The serum androgen bioactivity of the control and PA children, adult females, and males is presented in Figure 2. Circulating androgen bioactivity in the PA children was low, and there was no difference in the mean bioactivity between the PA and control children ( 0.33 vs. $0.33 \mathrm{nmol} / \mathrm{l} \mathrm{T}$ equivalents; not significant; Figure 2a). We found significant differences in the mean bioactivity between all children and adult females $(0.33$ vs. $0.73 \mathrm{nmol} / 1 \mathrm{~T}$ equivalents; $P=0.01$ ), as well as between the adult females and males ( 0.73 vs. $5.45 \mathrm{nmol} / \mathrm{l}$ T equivalents; $P$ $<0.001$; Figure 2b).

Mean serum androgen bioactivity levels, androgen, and sex hormone-binding globulin (SHBG) concentrations as well as the Vermeulen free androgen index (22) in the PA and control children, and in the adult females and males, are presented in Table 1. Among the children in whom the serum T concentrations were over the assay sensitivity (0.35 nmol/l) accompanied by a signal in the androgen bioassay $(n=28)$, we found a positive correlation between androgen bioactivity and serum

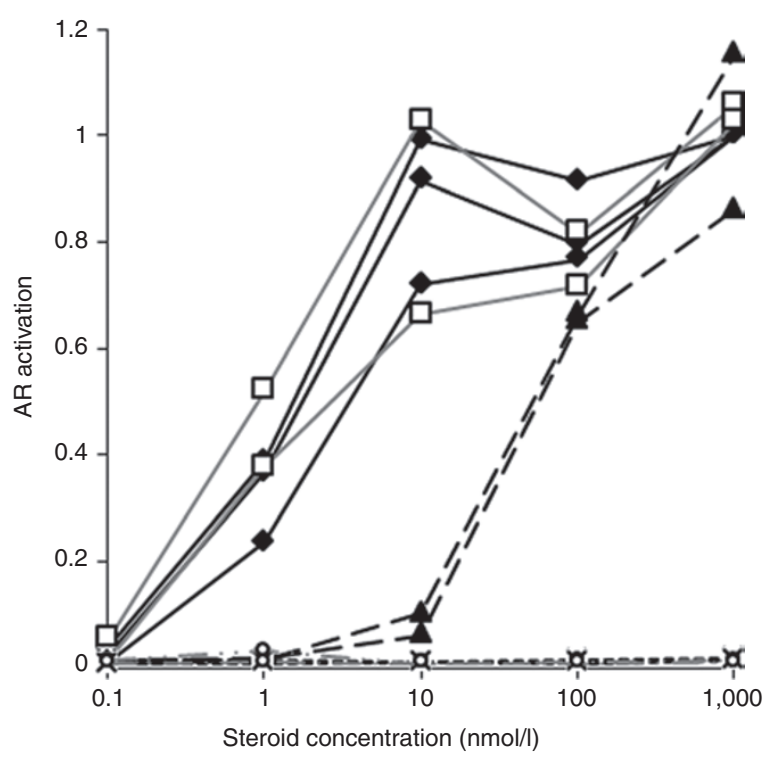

Figure 1. Androgen receptor (AR) activation by different androgens as assessed by luciferase (LUC) reporter gene assays in COS-1 cells. Results are shown relative to the LUC activity of pPB(-285/+32)-LUC in the presence of $1 \mu \mathrm{mol} / \mathrm{I}$ testosterone ( $\mathrm{T}$ ) set as 1 . Each line represents a different experiment. T was studied thrice and the other steroids twice. Filled diamond, T; open square, dihydrotestosterone; filled triangle, androstenedione; capital x, dehydroepiandrosterone; open circle, dehydroepiandrosterone sulfate.

T concentration $(r=0.50 ; P<0.01)$ and free androgen index $(r$ $=0.61 ; P<0.01)$ and a negative correlation between androgen bioactivity and serum SHBG concentration $(r=-0.41 ; P<0.05)$. There was also a significant correlation between androgen bioactivity and serum T (but not SHBG; $r=0.59 ; P<0.01$ ) and free androgen index $(r=0.61 ; P<0.01)$ in all girls selected using the same criteria $(n=25)$. Because only three boys met these criteria, we were unable to calculate any correlations in this subgroup. Of the PA children selected using the same criteria $(n=17), 13$ children (76\%) had pubarche, whereas of the remaining 52 children, only 19 (37\%) had pubarche $(P<0.05)$. We did not find any correlations between androgen bioactivity and serum DHEAS, DHEA, or A4 concentrations. In all children, T concentrations correlated negatively with SHBG $(r=-0.23$; $P<0.01)$ and positively with DHEA $(r=0.47 ; P<0.001)$, DHEAS $(r=0.42 ; P<$ $0.001)$, and A4 $(r=0.53 ; P<0.001)$ concentrations.

\section{DISCUSSION}

Our study supports the hypothesis that peripheral conversion of weak adrenal androgens is essential for the clinical androgenic effects in PA. Measured circulating androgen bioactivity in children with PA was low without differing significantly from that of the control children, albeit the sensitivity of our assay was not optimal for any definite conclusions. In those PA children who produced some signal in the androgen bioassay and measurable serum $\mathrm{T}$ levels in radioimmunoassay, pubarche was more common than in the other PA children. We also found that in the subgroup of all children with measurable serum $\mathrm{T}$ concentration and androgen bioactivity, bioactivity correlated with $\mathrm{T}$ and free androgen index. As expected, an 
a

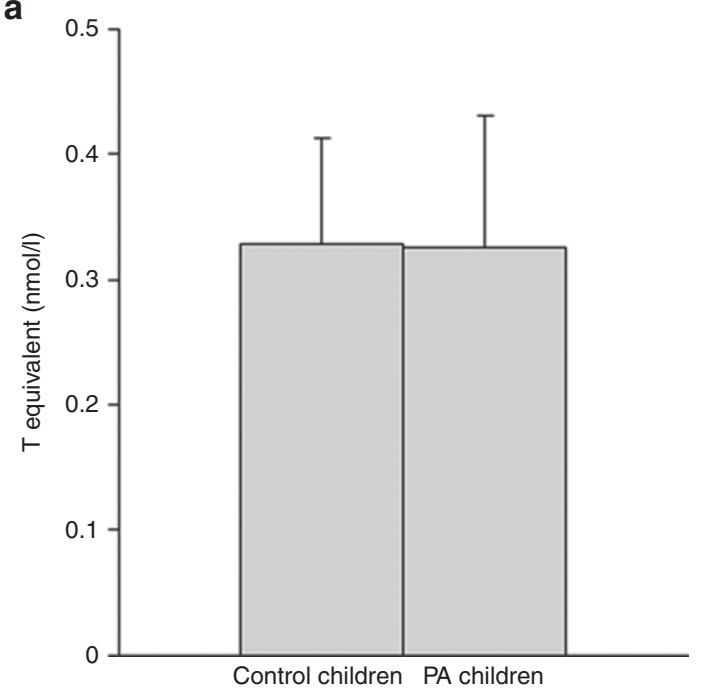

b

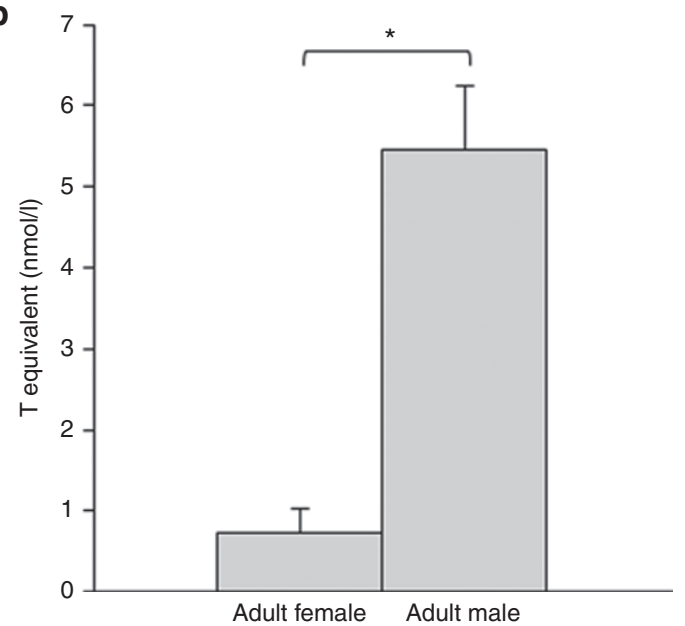

Figure 2. Mean (95\% confidence interval) serum androgen bioactivity (testosterone $(\mathrm{T})$ equivalent, $\mathrm{nmol} / \mathrm{l}$ ) in (a) children and (b) adults. ${ }^{*} P=0.01 . P A$, premature adrenarche.

inverse correlation between serum androgen bioactivity and SHBG concentration was also found. However, serum androgen bioactivity was not correlated with serum DHEAS or A4 concentrations in any subgroup of children.

PA is characterized by clinical signs of androgenic activity that do not correlate well with circulating adrenal androgen concentrations: children may have these signs alongside relatively low circulating DHEAS levels, or they may have increased DHEAS concentrations without any phenotypic signs $(3,23,24)$. The peripheral intracrine metabolism of weak adrenal androgen metabolites is known to be essential for the relevant androgenic effects. Approximately $30-50 \%$ of total androgens in men and $75-100 \%$ in women (pre- vs. postmenopausal, respectively) are thought to be formed in peripheral tissues from these adrenal precursor steroids $(9,11)$. In addition to peripheral tissues, HSD17B, an enzyme able to convert A4 to $\mathrm{T}$, is expressed in the liver (25) and even in the adrenal cortex (26). Rijk et al. (27) exposed bovine liver slices to DHEA and found increased androgen bioactivity and levels of A4 and T in cell culture media, suggesting the expression of converting enzymes in hepatic cells, but there is also evidence that steroid sulfatase is not active in human hepatic cells (5). Hui et al. (17) observed the expression of HSD17B5 in the ZR of human adrenals in children aged $9 \mathrm{y}$, and found that the thickness of ZR correlated with the expression of this enzyme. However, it is not yet known whether adrenal androgens are converted to potent androgens in the human liver or to what extent ZR in the human adrenal cortex is capable of synthesizing potent androgens (18). One would expect to find increased circulating bioactivity in children with PA if more potent androgens were secreted, or converted to the circulation, during adrenarche. As the currently available serum assays for T and DHT have limited sensitivity for pediatric serum samples, we wanted to test this hypothesis using a new method that takes into account the whole circulating serum androgenic pool. Our results suggest that peripheral intracrine metabolism in target tissues is essential for an androgenic impact in children with PA. Our present results are in line with previous findings in children with 21-hydroxylase deficiency who had low serum androgen bioactivity despite an increased serum level of adrenal A4 and clinical signs of androgenic activity (28).

In the peripheral tissues, increased androgen activity could be explained by changes in target tissue metabolism and increased AR activation. One possible way to increase DHT synthesis from adrenal androgens in peripheral tissues is the so-called alternative backdoor pathway found in patients with 21-hydroxylase deficiency (29). This route bypasses both androstenedione and $\mathrm{T}$ as intermediates. The transactivation efficacy of the AR is also crucial in the pathogenesis of PA as genetic variants of the $A R$ gene have been associated with PA (12). Finally, the transcriptional efficacy of the AR is also highly modulated by a wide range of different coactivators and repressors (30), but there are no studies on their role in PA.

The positive correlation between androgen bioactivity and serum $\mathrm{T}$ concentrations in all children who had measurable $\mathrm{T}$ levels reflects either minor gonadal androgen production or efficient conversion of DHEA, DHEAS, and A4 to circulating $\mathrm{T}$ in these children. The inverse correlation between SHBG and androgen bioactivity was expected, as only androgens not bound to SHBG are biologically active (31).

The bioassay used was designed to be as sensitive as possible, and indeed, its sensitivity was adequate for adult female and male samples. However, though the assay determines the activity of the whole serum androgenic pool, it was still too weak to detect small increases in androgen bioactivity in pediatric serum samples. When investigating androgen bioactivity using AR-based assays, the cell line should be selected carefully depending on the purpose of use. In our opinion, the COS-1 cell line was appropriate for this study because we wanted to investigate serum androgen bioactivity in the circulation, not at the target tissue level. If one wanted to study androgen bioactivity in target tissues, $\mathrm{CHO} 515$ or some other cell line with the expression of converting enzymes would be more appropriate (20). One weakness of all bioassay settings is that AR 
Table 1. Characteristics, serum androgen bioactivity, SHBG, and androgen concentrations in the control and all PA children (PA), PA children without pubarche (PA-PP), and in the adult females and males

\begin{tabular}{|c|c|c|c|c|c|}
\hline & \multicolumn{3}{|c|}{ Children } & \multicolumn{2}{|c|}{ Adult } \\
\hline & Control $(n=97)$ & $\mathrm{PA}(n=73)$ & $\mathrm{PA}-\mathrm{PP}(n=38)$ & Female $(n=16)$ & Male $(n=24)$ \\
\hline Age (y) & $7.60(6.90-8.17)$ & $7.47(7.00-8.02)$ & $7.21(6.72-7.68)^{*}$ & $21.08(20.50-21.65)$ & $20.58(20.44-21.25)$ \\
\hline $\mathrm{BMI}\left(\mathrm{kg} / \mathrm{m}^{2}\right)$ & $16.30(15.05-18.00)$ & $17.60(15.75-20.88)^{* *}$ & $17.23(15.40-19.33)$ & $21.52(20.67-26.83)$ & $23.17(19.98-28.63)$ \\
\hline BMI-SD scores & $0.15(-0.64$ to 0.95$)$ & $0.72(-0.10 \text { to } 1.97)^{* *}$ & $0.61(-0.38$ to 1.53$)$ & $0.22(-0.6$ to 1.55$)$ & $0.34(-0.62$ to 1.48$)$ \\
\hline Bioactivity (T equivalent) & $0.00(0.00-0.81)^{\mathrm{a}}$ & $0.00(0.00-0.79)^{\mathrm{b}}$ & $0.00(0.00-0.47)^{c}$ & $0.91(0.05-1.27)$ & $4.92(4.31-6.01)$ \\
\hline DHEA (nmol/l) & $4.10(2.60-6.10)$ & $7.10(4.85-9.95)^{\dagger}$ & $5.65(4.45-8.08)^{+}$ & No data & No data \\
\hline DHEAS ( $\mu \mathrm{mol} / \mathrm{l})$ & $0.70(0.50-1.30)$ & $1.65(1.15-2.55)^{\dagger}$ & $1.50(1.00-2.10)^{\dagger}$ & $8.25(4.85-9.28)$ & $10.30(8.73-12.38)$ \\
\hline A4 (nmol/l) & $1.45(0.83-2.20)$ & $2.70(1.75-3.55)^{\dagger}$ & $1.90(1.20-3.03)^{* *}$ & $10.39(9.60-12.05)$ & $10.38(8.92-12.15)$ \\
\hline $\mathrm{T}(\mathrm{nmol} / \mathrm{l})$ & $0.35(0.35-0.45)$ & $0.42(0.35-0.57)^{* *}$ & $0.35(0.35-0.44)$ & $1.83(1.62-2.50)$ & $23.80(20.38-32.00)$ \\
\hline SHBG $(\mathrm{nmol} / \mathrm{l})$ & $102.00(80.50-121.00)$ & $72.00(53.00-99.50)^{\dagger}$ & $95.50(62.00-128.25)$ & $59.00(47.25-63.75)$ & $26.50(17.50-37.75)$ \\
\hline $\mathrm{FAI}$ & $0.38(0.32-0.53)$ & $0.61(0.39-1.03)^{\dagger}$ & $0.43(0.27-0.63)$ & $2.93(2.33-5.94)$ & $92.20(73.65-125.38)$ \\
\hline
\end{tabular}

Values are expressed as median (interquartile range). BMI-SD scores were calculated with new Finnish growth references (36). Statistical differences between the PA or PA-PP groups and controls: ${ }^{*} P<0.05,{ }^{* *} P<0.01,{ }^{\dagger} P<0.001$.

A4, androstenedione; DHEA, dehydroepiandrosterone; DHEAS, dehydroepiandrosterone sulfate; FAl, free androgen index; PA, premature adrenarche; PP, premature pubarche; SHBG, sex hormone-binding globulin; T, testosterone. ${ }^{a} n=94 .{ }^{b} n=67 .{ }^{c} n=34$.

transactivation is dependent on coactivator and corepressor mixtures varying in different cell types, and their impact varies with different promoters.

The limitations in the sensitivity of the developed bioassay may hide some differences between the PA and control children. However, serum androgen bioactivity in children with PA seems to be low, which supports the hypothesis that peripheral conversion of adrenal androgens is important for the androgenic signs seen in PA. More studies are needed to investigate the genetic variations, coregulators, and factors that modulate this peripheral conversion in children with PA.

\section{METHODS}

\section{Subjects and Serum Assays}

Children participating in our PA study have been presented previously (3). From this group, we studied serum samples of $73 \mathrm{prepu}-$ bertal children with PA (mean age: 7.45 y, SD: 0.92 y, 10 boys) and 97 healthy control children (mean age: 7.49 y, SD: 0.89 y, 18 boys). Six PA and three control children did not provide enough serum for the bioassay, so the final number of children for this study was 67 (9 boys) PA and 94 (18 boys) control children; their characteristics are depicted in Table 1. In this study, the definition of PA was purely clinical, and the inclusion criteria for the PA group were any sign(s) of adrenarche, including pubic/axillary hair, acne, comedones, adult-type body odor, or oily hair, before the age of $8 \mathrm{y}$ in girls and $9 \mathrm{y}$ in boys. Other causes of androgen excess (central puberty, congenital adrenal hyperplasia, adrenocortical tumor) were excluded via clinical examination and gonadotropin-releasing hormone test, short Synacthen (Defiante Pharmaceutica S.A., Funchal, Portugal) test with 17-hydroxyprogesterone measurements, and abdominal ultrasonography.

We also examined serum samples from 40 healthy young adults who were not undergoing any hormonal treatment (16 females, mean age: 21.09 y, SD: 0.74 y; 24 males, mean age: 20.75 , SD: 0.51 y). Twenty-one of these ( 7 females and 14 males) had been born small for gestational age because this group was originally recruited to investigate the outcomes of babies born small for gestational age (32).

Serum DHEAS and A4 concentrations were determined using specific Coat-A-Count radioimmunoassays (RIAs) (Diagnostic Products, Los Angeles, CA). Serum DHEA concentrations were measured using an in-house RIA derived from a previously described method (3) and
T concentrations using a commercial RIA (Diagnostic Products). SHBG was determined using a specific time-resolved fluoroimmunoassay by AutoDelfia (PerkinElmer Life and Analytical Sciences Wallac Oy, Turku, Finland).

The study protocol was approved by the Research Ethics Committee of Kuopio University Hospital (Kuopio, Finland). Informed written consents from the study subjects or their parents and assents from the children were obtained for participation in the study.

\section{Bioassay}

Plasmids and steroids. The AR-responsive reporter $\mathrm{pPB}(-285 /+32)$ LUC and AR expression vector $\mathrm{pSG5}-\mathrm{hAR}$ are described elsewhere $(33,34)$. The internal control pCMV $\beta$ ( $\beta$-galactosidase under the control of constitutive cytomegalovirus promoter expression vector) was from Clontech (Palo Alto, CA). DHEA, DHEAS, A4, T, and DHT were provided by Steraloids (London, UK).

Cell culture and transfection. COS-1 cells (ATCC, Manassas, VA) represent a fibroblast-like cell line derived from African green monkey kidney, which does not naturally express the converting enzymes of adrenal androgens (19). The cells were cultured in Dulbecco's modified eagle medium (Gibco, Invitrogen, part of Life Technologies, Carlsbad, CA) with phenol red containing $10 \%$ (vol/vol) fetal calf serum (FCS; HyClone, part of Thermo Fisher Scientific, Waltham, MA), penicillin (25 U/ml; Gibco, Paisley, Scotland), and streptomycin $(25 \mu \mathrm{g} / \mathrm{ml}$; Gibco). The cells were seeded onto 96-well plates (Greiner Bio-One GmbH, Frickenhausen, Germany) at a density of 5,000 cells per well. They were then incubated overnight at $37^{\circ} \mathrm{C}$ in a humidified atmosphere ( $\left.5 \% \mathrm{CO}_{2}\right)$, and the cell culture medium was replaced with phenol red-free Dulbecco's modified eagle medium containing $25.6 \mathrm{mmol} / \mathrm{l}$ glucose (MP Biomedicals LLC, Solon, OH), $3.4 \mathrm{mmol} / \mathrm{l}$ L-glutamine (Gibco), $51.2 \mathrm{U} / \mathrm{ml}$ penicillin (Gibco), $51.2 \mu \mathrm{g} / \mathrm{ml}$ streptomycin (Gibco), and 10\% (vol/vol) charcoal-stripped FCS. Finally, $28 \mathrm{~h}$ after plating, the cells were transfected using TransIT-LT1 transfection reagent (Mirus Bio LLC, Madison, WI). Each well received a total of $68.3 \mathrm{ng}$ DNA (pPB(-285/+32)-LUC: $39.0 \mathrm{ng}$; pSG5-hAR: $22.8 \mathrm{ng}$; pCMVß: $6.5 \mathrm{ng}$ ).

Preparation of standards and patient sera for the bioassay. T was first diluted with ethanol and then added to charcoal-stripped FCS. The solution $(100 \mathrm{nmol} / \mathrm{l})$ was then aliquoted and stored at $-70{ }^{\circ} \mathrm{C}$ for future use as a standard in the bioassay. In the experiments, standard aliquots were diluted by mixing with FCS (1/1), to obtain six different concentrations $(0.78,1.56,3.125,6.25,12.5$, and $25 \mathrm{nmol} / \mathrm{l})$. The serum samples were prepared by centrifuging $(2 \times 2 \mathrm{~min}, 13,000 \mathrm{rpm}$, rotated 
$180^{\circ}$ after $\left.2 \mathrm{~min}\right) 45 \mu \mathrm{l}$ of each sample in a $0.22-\mu \mathrm{m}$ cellulose acetate Spin-X centrifuge filter unit (Corning Costar, Corning, NY). Pooled serum from study participants was made to determine the coefficients of variation of repeated measurements.

Treatment of the cells. Twenty-four hours after transfection, the medium in each well was replaced with $90 \mu \mathrm{l}$ of phenol red-free Dulbecco's modified eagle medium containing $28.4 \mathrm{mmol} / \mathrm{l}$ glucose, $3.8 \mathrm{mmol} / \mathrm{l} \mathrm{L}$-glutamine, $56.8 \mathrm{U} / \mathrm{ml}$ penicillin, and $56.8 \mu \mathrm{g} / \mathrm{ml}$ streptomycin, to which $10 \mu \mathrm{l}$ of T standard in FCS in duplicate or $10 \mu \mathrm{l}$ of human serum sample in triplicate was added. As an internal control, we used two nontransfected wells per plate.

Measurement of activity. After an overnight incubation $\left(37^{\circ} \mathrm{C}, 5 \%\right.$ $\mathrm{CO}_{2}$ ), the cells were lysed in reporter lysis buffer (Promega, Madison, WI) and LUC activity was measured with the LUC assay system (Promega) using the Luminoskan Ascent luminometer (Thermo Fisher Scientific, Waltham, MA). The activity of $\beta$-galactosidase was determined as previously described (35). For each sample, LUC activity was divided by $\beta$-galactosidase to correct for differences in transfection efficiency. Samples were measured blinded to the clinical and endocrinological status of the subjects.

AR activation by various steroid compounds. Cell culture, transfection, and activity measurements were performed using the same protocol as used with human serum samples. Each androgen (DHEA, DHEAS, A4, T, and DHT) was dissolved in ethanol and diluted by mixing with charcoal-stripped FCS to obtain 10 different concentrations $(0.05,0.1,0.5,1,5,10,50,100,500$, and $1,000 \mathrm{nmol} / \mathrm{l})$. Bioactivity induced by $\mathrm{T}$ was measured thrice and that induced by the other steroids was measured twice.

\section{Statistical Analysis and Sensitivity of the Bioassay}

Standard curves followed a quadratic curve (Mean Rsq: 0.988; SD: $0.008 ; P<0.01)$ with small amounts of $\mathrm{T}(0.78-25 \mathrm{nmol} / \mathrm{l})$. Bioactivity in the human serum samples was compared with the standards and expressed in T equivalents (nmol/l). The MannWhitney $U$ test was used to compare bioactivity scores for different groups. When investigating the relationship between different variables, Spearman's correlation coefficient was used, and relative LUC activity below the sensitivity of the bioassay was set at zero $\mathrm{T}$ equivalent (97 child and 4 adult female samples). The difference in the prevalence of pubarche between the study groups was analyzed using the $\chi^{2}$ test. All statistical analyses were performed using SPSS 19.0 (SPSS, Chicago, IL).

In most child or adult female samples, bioactivity was below our lowest standard dilution ( $\mathrm{T}=0.8 \mathrm{nmol} / \mathrm{l})$. Therefore, we defined the sensitivity of this assay as the mean LUC activity (of repeated measures) induced by FCS without added $\mathrm{T}(\mathrm{T}=0 \mathrm{nmol} / \mathrm{l})$. Intra- and interassay coefficients of variation were defined as repeated measurements of the same pooled sera. The interassay coefficient of variation was $35 \%$ (14 runs), and the intraassay coefficient of variation was $15 \%$.

\section{ACKNOWLEDGMENTS}

Alise Tapio is thanked for her careful assistance in the laboratory studies.

\section{STATEMENT OF FINANCIAL SUPPORT}

This work was supported by Kuopio University Hospital (Kuopio, Finland), The Foundation for Pediatric Research (Helsinki, Finland), The National Graduate School of Clinical Investigation (Helsinki, Finland), The Finnish Medical Foundation (Helsinki, Finland), and The Sigrid Jusélius Foundation (Helsinki, Finland).

Disclosure: The authors declare no conflict of interest.

\section{REFERENCES}

1. Dhom G. The prepuberal and puberal growth of the adrenal (adrenarche). Beitr Pathol 1973;150:357-77.

2. Paterson WF, Ahmed SF, Bath L, et al. Exaggerated adrenarche in a cohort of Scottish children: clinical features and biochemistry. Clin Endocrinol (Oxf) 2010;72:496-501.
3. Utriainen P, Voutilainen R, Jäskeläinen J. Continuum of phenotypes and sympathoadrenal function in premature adrenarche. Eur J Endocrinol 2009; 160:657-65.

4. Reed MJ, Purohit A, Woo LW, Newman SP, Potter BV. Steroid sulfatase: molecular biology, regulation, and inhibition. Endocr Rev 2005;26:171202.

5. Hammer F, Subtil S, Lux P, et al. No evidence for hepatic conversion of dehydroepiandrosterone (DHEA) sulfate to DHEA: in vivo and in vitro studies. J Clin Endocrinol Metab 2005;90:3600-5.

6. Chen F, Knecht K, Birzin E, et al. Direct agonist/antagonist functions of dehydroepiandrosterone. Endocrinology 2005;146:4568-76.

7. Brinkmann AO. Molecular mechanisms of androgen action-a historical perspective. Methods Mol Biol 2011;776:3-24.

8. Chen F, Knecht K, Leu C, et al. Partial agonist/antagonist properties of androstenedione and 4-androsten-3beta,17beta-diol. J Steroid Biochem Mol Biol 2004;91:247-57.

9. Labrie F, Luu-The V, Labrie C, Simard J. DHEA and its transformation into androgens and estrogens in peripheral target tissues: intracrinology. Front Neuroendocrinol 2001;22:185-212.

10. Toda K, Simpson ER, Mendelson CR, Shizuta Y, Kilgore MW. Expression of the gene encoding aromatase cytochrome P450 (CYP19) in fetal tissues. Mol Endocrinol 1994;8:210-7.

11. Labrie F, Bélanger A, Simard J, Van Luu-The, Labrie C. DHEA and peripheral androgen and estrogen formation: intracinology. Ann N Y Acad Sci 1995;774:16-28.

12. Lappalainen $S$, Utriainen $P$, Kuulasmaa $T$, Voutilainen $R$, Jääskeläinen $J$. Androgen receptor gene CAG repeat polymorphism and X-chromosome inactivation in children with premature adrenarche. J Clin Endocrinol Metab 2008;93:1304-9.

13. Ibáñez L, Ong KK, Mongan N, et al. Androgen receptor gene CAG repeat polymorphism in the development of ovarian hyperandrogenism. J Clin Endocrinol Metab 2003;88:3333-8.

14. Petry CJ, Ong KK, Michelmore KF, et al. Associations between common variation in the aromatase gene promoter region and testosterone concentrations in two young female populations. J Steroid Biochem Mol Biol 2006;98:199-206.

15. Petry CJ, Ong KK, Wingate DL, de Zegher F, Ibáñez L, Dunger DB. Lack of association between common polymorphisms in the 17beta-hydroxysteroid dehydrogenase type $\mathrm{V}$ gene (HSD17B5) and precocious pubarche. J Steroid Biochem Mol Biol 2007;105:176-80.

16. Wang L, Salavaggione E, Pelleymounter L, Eckloff B, Wieben E, Weinshilboum R. Human 3beta-hydroxysteroid dehydrogenase types 1 and 2: Gene sequence variation and functional genomics. J Steroid Biochem Mol Biol 2007;107:88-99.

17. Hui XG, Akahira J, Suzuki T, et al. Development of the human adrenal zona reticularis: morphometric and immunohistochemical studies from birth to adolescence. J Endocrinol 2009;203:241-52.

18. Rege J, Rainey WE. The steroid metabolome of adrenarche. J Endocrinol 2012;214:133-43.

19. Raivio T, Palvimo JJ, Dunkel L, Wickman S, Jänne OA. Novel assay for determination of androgen bioactivity in human serum. J Clin Endocrinol Metab 2001;86:1539-44.

20. Paris F, Servant N, Térouanne B, Sultan C. Evaluation of androgenic bioactivity in human serum by recombinant cell line: preliminary results. Mol Cell Endocrinol 2002;198:123-9.

21. Rodriguez PC, Yee DJ, Sames D. Expanding the use of fluorogenic enzyme reporter substrates to imaging metabolic flux changes: the activity measurement of 5a-steroid reductase in intact mammalian cells. ACS Chem Biol 2010;5:1045-52.

22. Vermeulen A, Verdonck L, Kaufman JM. A critical evaluation of simple methods for the estimation of free testosterone in serum. J Clin Endocrinol Metab 1999;84:3666-72.

23. Rosenfield RL. Normal and almost normal precocious variations in pubertal development premature pubarche and premature thelarche revisited. Horm Res 1994;41:Suppl 2:7-13.

24. Vottero A, Capelletti M, Giuliodori S, et al. Decreased androgen receptor gene methylation in premature pubarche: a novel pathogenetic mechanism? J Clin Endocrinol Metab 2006;91:968-72. 


\section{Articles | Limatta et al.}

25. Labrie F, Luu-The V, Lin SX, et al. The key role of 17 beta-hydroxysteroid dehydrogenases in sex steroid biology. Steroids 1997;62:148-58.

26. Nakamura Y, Hornsby PJ, Casson P, et al. Type 5 17beta-hydroxysteroid dehydrogenase (AKR1C3) contributes to testosterone production in the adrenal reticularis. J Clin Endocrinol Metab 2009;94:2192-8.

27. Rijk JC, Bovee TF, Peijnenburg AA, Groot MJ, Rietjens IM, Nielen MW. Bovine liver slices: A multifunctional in vitro model to study the prohormone dehydroepiandrosterone (DHEA). Toxicol In Vitro 2012; 26:1014-21.

28. Hero M, Jänne OA, Näntö-Salonen K, Dunkel L, Raivio T. Circulating antiandrogenic activity in children with congenital adrenal hyperplasia during peroral flutamide treatment. J Clin Endocrinol Metab 2005;90:5141-5.

29. Kamrath C, Hochberg Z, Hartmann MF, Remer T, Wudy SA. Increased activation of the alternative "backdoor" pathway in patients with 21-hydroxylase deficiency: evidence from urinary steroid hormone analysis. J Clin Endocrinol Metab 2012;97:E367-75.

30. Heinlein CA, Chang C. Androgen receptor (AR) coregulators: an overview. Endocr Rev 2002;23:175-200.
31. Siiteri PK, Murai JT, Hammond GL, Nisker JA, Raymoure WJ, Kuhn RW. The serum transport of steroid hormones. Recent Prog Horm Res 1982;38:457-510.

32. Todorova B, Salonen M, Jäskeläinen J, et al. Adrenocortical hormonal activity in 20-year-old subjects born small or appropriate for gestational age. Horm Res Paediatr 2012;77:298-304.

33. Palvimo JJ, Reinikainen P, Ikonen T, Kallio PJ, Moilanen A, Jänne OA. Mutual transcriptional interference between RelA and androgen receptor. J Biol Chem 1996;271:24151-6.

34. Adeyemo O, Kallio PJ, Palvimo JJ, Kontula K, Jänne OA. A single-base substitution in exon 6 of the androgen receptor gene causing complete androgen insensitivity: the mutated receptor fails to transactivate but binds to DNA in vitro. Hum Mol Genet 1993;2:1809-12.

35. Makkonen H, Jääskeläinen T, Rytinki MM, Palvimo JJ. Analysis of androgen receptor activity by reporter gene assays. Methods Mol Biol 2011;776:71-80.

36. Saari A, Sankilampi U, Hannila ML, Kiviniemi V, Kesseli K, Dunkel L. New Finnish growth references for children and adolescents aged 0 to 20 years: Length/height-for-age, weight-for-length/height, and body mass indexfor-age. Ann Med 2011;43:235-48. 